Additional evidence is important because a few vocal sceptics are working to undo the Montreal Protocol, a treaty that is already slowing the growth in stratospheric chlorine ${ }^{8}$. These few ignore the weight of scientific evidence, parrot misconceptions that have been thoroughly scrutinized and discredited, focus attention only on the few studies that support their position, and predict that the Montreal Proto-

1 Russell, J. M., Luo, M., Cicerone, R. J. \& Deaver, L. E. Nature 379, 526-529 (1996)

2. WMO, Scientific Assessment of Ozone Depletion: 1994 Report No. 37, World Meteorological Organization Global Ozone Research and Monitoring Project (1995).

3. Gunson, M. R. et al. Geophys. Res. Lett. 21, 2223-2226 (1994).

OBITUARY col will cause economic distress and a worldwide reduction in living standards. By their statements, they have confused the press, the public and members of government.

Deciding whether CFCs affect stratospheric ozone should not be a matter of personal prejudice, but of examining the evidence and drawing conclusions. The conclusion of scientists who have made

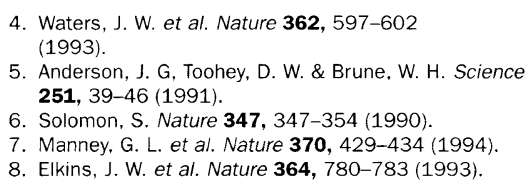

the effort honestly to study the evidence is that the use of CFCs has resulted in the loss of stratospheric ozone - certainly in the Antarctic ozone hole and the Arctic wintertime stratosphere, and probably over middle latitudes as well. As Russell et al. have said, "Any attempts to conclude otherwise must explain away the scientific evidence provided in this paper". Those who do not believe must provide alternative explanations if future discussions are to be based on science, not politics.

William Brune is in the Department of Meteorology, Pennsylvania State University, University Park, Pennsylvania 16802, USA.

\title{
Clair C. Patterson (1922-95)
}

Clair C. (Pat) Patterson died suddenly at his home early in the morning on 5 December 1995 . His main contributions to science were the discovery of the age of the Earth and his pioneering studies of global lead contamination. That research, which won him the Tyler Prize for Environmental Achievement, catalysed an unprecedented worldwide policy shift banning lead in gasoline and manufactured products.

Just as Saul Bellow portrayed him in the novel The Dean's December, where Patterson appears as Sam Beech, he was justifiably proud of his rural midwestern heritage. Born and raised in lowa, he earned an AB in chemistry at Grinnell College in 1943, an MS at the University of lowa in 1944, and a PhD at the University of Chicago in 1951. During that period, he also met two of the people who enabled his scientific career to flourish for half a century: his wife Lorna, whose serenity perfectly complemented Pat's intensity, and his mentor, Harrison Brown, who created an ideal intellectual environment for Patterson to thrive, first at Chicago and later at the California Institute of Technology.

Patterson determined that the Earth and the Solar System are 4.6 billion years old by measuring stable lead isotopes - produced by the radioactive decay of uranium and thorium - in a meteorite, which he assumed had been formed at the same time. This was far older than previous estimates of approximately three billion years accepted at the time. He used the same isotopic techniques to investigate the evolution of the Earth's crust.

Those analyses required the development of 'clean techniques' to eliminate the surprisingly large amounts of contaminant lead in his samples. $\mathrm{He}$ traced the contamination to industrial sources, and redirected his research to quantifying the magnitude of anthro- pogenic lead emissions on a global scale. He found that the emissions began with the smelting of lead ores five thousand years ago, and increased markedly with the addition of lead alkyls to gasoline this century. His analyses of temporal variations of lead

\section{IMAGE UNAVAILABLE FOR COPYRIGHT REASONS}

in ice cores, sediments, oceans, atmospheres and organisms demonstrated that contemporary lead concentrations in the biosphere are often orders of magnitude above the natural levels deduced from comparing the ratio of lead to its biochemical analogue, calcium, in pristine and contaminated tissues. Patterson also put those increases into perspective by showing that lead concentrations in humans are now 500 to 1,000 times pre-industrial levels, and by noting that no threshold concentration for lead toxicity in humans has been established.

His meticulous documentation of lead contamination was initially controversial. Malicious attacks were directed at him by many people because his analyses invalidated their data or their ideas and revealed the enormous societal costs of environmental lead contamination. However, all of Patterson's research has now been corroborated. His methods have revolutionized environmental and medical research, where clean techniques reveal structure in the biogeochemical cycles of other trace elements, at environmental concentrations often orders of magnitude lower than earlier experiments could have detected.

Patterson was an iconoclast, but as a very private man he disliked being a public figure. At Caltech, he assumed the unique title of Geochemist rather than accept an endowed chair that might interfere with his research. Although he ignored his critics, he was very concerned with the expanding influence of pseudoscientists (whom he classified as degenerative hominids) on future generations of scientists. He was also obsessed with the collegiality, integrity and worth of science, as illustrated in his preface to the volume of Geochimica et Cosmochimica Acta (1994) dedicated to him:

True scientific discovery renders the brain incapable, at such moments, of shouting victoriously to the world "Look at what I have done! Now I will reap rewards of recognition and wealth!" Instead such discovery instinctively forces the brain to thunder "WE did it!" in a voice no one else can hear within its sacred but lonely chapel of scientific thought. In that shrine a lasting sense of well-being is conferred through electrifying recognition that the human mind, to which community the scientific mind belongs, does indeed reign supreme over the physical world through its ability to develop understandings of that world's secrets, not to find ways to control it.

Clair Patterson was a scientist for the ages. We will miss him dearly.

A. Russell Flegal

A. Russell Flegal is in the Department of Earth Science, University of California, Santa Cruz, California 95064, USA. 